\title{
Role of Glutathione in Winemaking: A Review
}

\author{
Engela C. Kritzinger, ${ }^{\dagger}$ Florian F. Bauer, ${ }^{\dagger \dagger}$ and Wessel J. du Toit* ${ }^{\dagger}$ \\ ${ }^{\dagger}$ Department of Viticulture and Oenology and ${ }^{\ddagger}$ Institute of Wine Biotechnology, Stellenbosch University, Private Bag X1, Matieland, \\ 7602 Stellenbosch, South Africa
}

ABSTRACT: Glutathione is an important constituent of grapes, must, and wine. However, to date, no review has provided an integrated view of the role of this compound in wine-related systems. In this review, special emphasis is given to its occurrence in grapes, must, and wine and its role as an antioxidant in wine. The effect of glutathione on both desirable and undesirable aroma compounds is also outlined. Furthermore, the use of glutathione-enriched products in winemaking and the various analytical techniques for the quantification of glutathione in must and wine are discussed. Limitations in existing knowledge are also identified.

KEYWORDS: glutathione, wine, antioxidant

\section{INTRODUCTION}

Glutathione $(\mathrm{GSH})$ is a tripeptide of L-glutamate, L-cysteine, and glycine. It is the most abundant nonprotein intracellular thiol $(0.2-10 \mathrm{mM})$ present in mammalian and many prokaryotic organisms. ${ }^{1}$ Its biological significance is mostly related to its free sulfhydryl moiety of the cysteine residue, which confers unique redox and nucleophilic properties. ${ }^{2} \mathrm{GSH}$ can occur in the cell as the reduced form of GSH and in the oxidized form as glutathione disulfide (GSSG) (Figure 1) as well as mixed disulfides, GS-S-Cys and GS-S-CoA. ${ }^{3}$ Generally, $>90 \%$ of GSH is present in the reduced form in the cell. ${ }^{4}$ GSSG is formed upon oxidation of GSH. At the expense of NADPH, GSSG can be reduced back to GSH by glutathione reductase. ${ }^{5}$

The major functions of GSH can be summarized as being an antioxidant, immunity booster, and detoxifier. ${ }^{6}$ In living tissues, GSH plays a pivotal role in bioreduction, protection against oxidative stress, xenobiotics, and endogenous toxic metabolite detoxification, enzyme activity, and sulfur and nitrogen metabolism. ${ }^{7}$ It is thus considered as a powerful, versatile, and important self-generated-defense molecule. ${ }^{4}$

In wine, the role and application of glutathione have recently received significant scientific and commercial attention. The primary reason is related to the control of oxidative spoilage of wine. Indeed, oxidative spoilage of mostly white wine constitutes a well-known problem in the wine industry. White and, to a lesser degree, red wines are sensitive to oxygen exposure, which can lead to a loss in characteristic aroma, the development of atypical aging characters, and undesirable color changes. GSH plays an integral role in the oxidation of musts, where it traps $o$-quinones, formed during oxidation, to limit the amount of browning pigments. ${ }^{8-10}$ Furthermore, GSH exerts a protective effect on various aromatic compounds in wine. ${ }^{11-13}$ However, the supplementation of purified GSH to must during vinification is not allowed by current wine regulation. ${ }^{13}$ The aim of this review is to discuss and compare the scattered literature on glutathione in wine-related systems and to identify novel topics that merit further research.

\section{GLUTATHIONE IN GRAPES}

GSH is synthesized in the cytosol and chloroplasts of plant cells in two sequential ATP-dependent reactions. ${ }^{14} \gamma$-Glutamylcysteine is synthesized from L-glutamate and L-cysteine by $\gamma$ glutamylcysteine synthetase. GSH synthetase then catalyzes the addition of glycine to form GSH. ${ }^{15}$ GSH plays several physiological and biochemical roles in plants, the most important being redox control, detoxification, and sulfur metabolism. $^{16}$

GSH was first quantified in grapes in $1989 .{ }^{17}$ These authors conducted a study to analyze the GSH content of both the berries and the respective musts of 28 Vitis vinifera grape varieties. The GSH content varied from 56 to $372 \mu \mathrm{mol} / \mathrm{kg}$ $(17-114 \mathrm{mg} / \mathrm{kg})$ between grape varieties. These great variations among varieties, however, were not strictly dependent on variety alone. Vintage, location, and technological practices all influence the GSH content. ${ }^{17}$ GSH has been observed to increase at the onset of ripening of $V$. vinifera berries. This increase in GSH content was observed in green, red, seeded, and seedless varieties. The strong correlation between accumulated GSH and soluble solids persists until the berries reach $16{ }^{\circ}$ Brix, whereafter the GSH content remains stable. ${ }^{18}$ This result is consistent with findings by Okuda and Yokotsuka. ${ }^{19}$ Suklje et al. ${ }^{20}$ also found GSH levels to increase at higher sugar levels, with the berry diameter or bunch exposure not influencing GSH levels significantly. In addition, it was established that $>90 \%$ of the total glutathione in berries during ripening is in the reduced form. ${ }^{19}$ The authors postulated that the increase in GSH at the onset of ripening in berries may be ascribed to an increased contribution of phloem components to the berry from sources such as mature leaves. This is supported by another study which showed that the increase in berry GSH is accompanied by a decrease in leaf GSH content. ${ }^{21}$ It is uncertain if GSH can be synthesized in the berry itself, and therefore further research is necessary to establish the precise

Received: August 24, 2012

Revised: November 29, 2012

Accepted: December 17, 2012

Published: December 17, 2012 
A<smiles>NC(CCC(=O)NC(CS)C(=O)NCC(=O)O)C(=O)O</smiles>

B

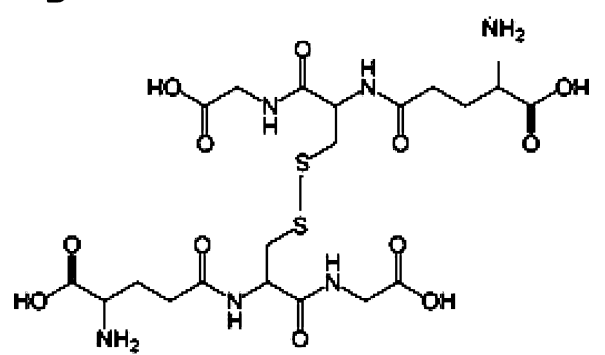

Figure 1. Molecular structures of (A) glutathione (GSH) and (B) glutathione disulfide (GSSG).

site of synthesis. GSH content in grapes is closely related to the vine nitrogen status estimated as yeast assimilable nitrogen content of the grape juice. The GSH content of must originating from nitrogen-deficient vines was significantly lower than that of must from vines that were fertilized after bloom. ${ }^{22}$ A late soil nitrogen fertilization at berry set resulted in juice with a 6-fold higher yeast assimilable nitrogen content compared to the control. This juice also contained higher cysteine conjugate precursors and GSH levels. The above results were confirmed in another study, which evaluated the impact of foliar nitrogen (LEAFN) and foliar nitrogen and sulfur (LEAFNS) applications on low nitrogen status Sauvignon blanc vines on wine GSH and wine volatile thiols. Both treatments resulted in juice with higher yeast assimilable nitrogen levels compared to the control. The GSH content of the wine from both treatments was also higher. However, the addition of sulfur to the foliar $\mathrm{N}$ spraying did not significantly increase the GSH content of the wine. ${ }^{23}$ Both of these studies were conducted on vines with low nitrogen status, and it is unknown whether the same results would be obtained if this study were conducted on vines with higher nitrogen status. Further research is also required to establish to what extent GSH levels can be manipulated in the vineyard.

\section{GLUTATHIONE IN MUST AND WINE}

GSH content in must is highly variable. Levels ranging from nondetectable to $100 \mathrm{mg} / \mathrm{L}$ have been reported in grape must. ${ }^{17,24}$ GSH levels in South African juice ranged from 1.1 to $71 \mathrm{mg} / \mathrm{L}$, which correlates well with values reported by other authors. ${ }^{25-29}$ Several factors can influence the GSH concentration in must, that is, exposure to oxygen, tyrosinase activity, grape skin maceration during the prefermentation period, and pressing. $^{25,26,30} \mathrm{Du}$ Toit et al. ${ }^{25}$ studied the effect of oxidative and reductive treatments during winemaking on the GSH concentration in South African white grape juice and the resulting wines. The reductive treatment $(<0.3 \mathrm{mg} / \mathrm{L}$ dissolved $\mathrm{O}_{2}$ pick-up during pressing) resulted in the highest GSH levels in the grape juice and the corresponding wine. The control (1$1.5 \mathrm{mg} / \mathrm{L}$ dissolved $\mathrm{O}_{2}$ added) and especially oxidative treatments $\left(3.5-4 \mathrm{mg} / \mathrm{L}\right.$ dissolved $\mathrm{O}_{2}$ added) displayed significant lower juice and wine GSH levels. Juice GSSG levels are generally much lower compared to GSH levels. Values reported ranged from 0.46 to $2.93 \mathrm{mg} / \mathrm{L} .{ }^{25}$ Oxidative handling of the juice led to significantly higher GSSG levels. This corroborates data from other studies, ${ }^{9,29,31}$ which all reported initial GSSG levels below $1 \mathrm{mg} / \mathrm{L}$. During machine harvesting, oxygen uptake is inevitable, which results in a decrease in juice GSH content. This is supported by the presence of moderate amounts of $S$-glutathionyl caftaric acid $(9-15 \mathrm{mg} / \mathrm{L})$ that was present in the free-run juice of machine-harvested Sauvignon blanc grapes. ${ }^{26}$ Free-run juice is characterized by higher GSH concentrations compared to higher press fractions. ${ }^{26,30}$ The GSH concentration of three different Sauvignon blanc juices collected after $1 \mathrm{~h}$ of skin contact in a winery trial had fallen by up to half. Moreover, only one of the three juice pressings obtained at 0.4 atm had detectable amounts of GSH left. ${ }^{26}$ Results regarding the evolution of GSH concentration during alcoholic fermentation of grape juice are contradictory. GSH concentrations have been observed to either increase ${ }^{24,29,32-35}$ or decrease during alcoholic fermentation. ${ }^{25,29,30,32,36} \mathrm{GSH}$, which is implicated in many stress response mechanisms in Saccharomyces cerevisiae such as sulfur and nitrogen starvation, oxidative stress, and the detoxification of heavy metals and xenobiotics, ${ }^{7}$ may be assimilated during alcoholic fermentation though transporters, which have already been characterized. ${ }^{37,38}$ Recently, a transporter for GSH secretion has also been characterized in S. cerevisiae. ${ }^{39}$ It can thus be postulated that the yeast could possibly alter the GSH content in wines by utilizing and secreting GSH during fermentation and that differences between strains in the quantities assimilated or secreted may result in various wine GSH contents. Lavigne et al. ${ }^{32}$ proposed that the amount of GSH present after alcoholic fermentation is dependent on the yeast strain. However, in an independent study by Fracassetti et al., ${ }^{34}$ the influence of yeast strain was regarded as insignificant.

On the other hand, another study showed that synthetic wines fermented with 20 different commercial wine yeast strains differed significantly in terms of GSH content, with certain strains resulting in a 7 -fold higher wine GSH content. ${ }^{29}$ However, when selected strains were inoculated in grape juice, the trends with regard to final GSH content were not always confirmed. The reasons for the variation in final GSH levels in different fermentation media remain unexplained, but are likely linked to grape juice metabolic complexity. Indeed, it is well established that many grape and yeast metabolites are either taken up or released by yeast during fermentation depending on complex, nonlinear interactions between the grape juice initial metabolic composition, the genetic background of the yeast strain, and the many environmental parameters that affect yeast growth such as temperature, $\mathrm{pH}$, and osmotic pressure. The grape juice fermentations, nevertheless, delivered valuable information regarding the evolution of GSH during alcoholic fermentation. It was shown that the GSH content fluctuated during alcoholic fermentation, with the time stage and degree of fluctuation depending on the yeast strain and initial GSH content of the juice. Small, but significant, differences in GSH content for wines fermented with different yeast strains were observed. ${ }^{29}$ This observation suggests not only that strains differ in their GSH metabolism and that GSH is assimilated at certain stages and released again at others during alcoholic 
fermentation but also that the metabolism of the yeast is likely to be influenced by the extracellular GSH content. Screening of more yeast strains in grape juice is recommended to produce more conclusive results. Screening in terms of yeast GSH metabolism on a molecular level would also be of great value. A major drawback of these studies was the lack of knowledge on the source of GSH during alcoholic fermentation, that is, what was derived from the grape juice and what amount was produced by the yeast. Future work should include the use of labeled GSH $\left({ }^{35} \mathrm{~S}\right)$, which could elucidate the fate of GSH during alcoholic fermentation.

Compared to juice GSH levels, lower, on par, and higher levels have been observed in the subsequent wines, highlighting the complexity and variability of the behavior of GSH during fermentation. ${ }^{24,25,29,32-36}$ Wine GSH levels ranging from nondetectable to as high as $70 \mathrm{mg} / \mathrm{L}$ have been described. ${ }^{28,29}$ Janes et al. ${ }^{27}$ reported that the average GSH level in 28 young Sauvignon blanc wines was found to be $12.5 \mathrm{mg} / \mathrm{L}$. The data suggest that GSSG levels, in general, remain low $(<2 \mathrm{mg} / \mathrm{L})$ during alcoholic fermentation. ${ }^{29,40}$ The GSH concentration generally decreases during wine aging. ${ }^{13,29,32,41}$ Results regarding the effect of yeast lees on GSH levels in wine are also contradictory. Lavigne et al. ${ }^{32}$ found that, during barrel aging of unracked Sauvignon blanc wines, the decrease in GSH concentration was lower compared to racked wines. This was attributed to the reducing properties of yeast lees, which impeded the oxidation of GSH. The depletion of GSH in wine was faster if racked wine was aged in new barrels as a result of the greater oxidation effect of new wood. This is in stark contrast to another study ${ }^{29}$ that clearly showed a significant decrease in GSH content during aging. Not only was this study $^{29}$ performed under reductive conditions, which would limit the oxidation of GSH, it was also proven that no GSH was released from the autolyzed yeast cells over a one year period as has been suggested by Dubourdieu and Lavigne-Cruège. ${ }^{11}$ Variable oxygen exposure during bottle aging can also influence the GSH concentration in wine. ${ }^{13}$ Sauvignon blanc wines exposed to lower oxygen levels during bottle aging consistently showed higher GSH concentrations compared to wines that were exposed to higher levels of oxygen during storage. This was attributed to the lower oxidation degree in wines with lower oxygen levels.

It is thus clear that the evolution of GSH during winemaking can change drastically and that the concentration can be manipulated by the winemaker by limiting oxidation throughout the vinification and aging process.

\section{ANTIOXIDANT ACTIVITY OF GLUTATHIONE IN MUST AND WINE: INHIBITION OF BROWNING}

Browning is an oxidative process occurring during the vinification of wine that detracts from its sensory properties of appearance, aroma, and flavor. ${ }^{42}$ Phenols, in particular $o$ diphenols, are responsible for the oxidative browning in wine. Browning can be a result of enzymatic oxidation, which almost entirely takes place in grape must, and nonenzymatic oxidation, also called chemical oxidation, that occurs predominantly during wine aging. ${ }^{43}$ Enzymatic browning in grape must is highly correlated with the hydroxycinnamate content of the juice, presenting the main group of phenolic compounds in white juice. ${ }^{42,44}$ Caftaric (caffeoyl tartaric) acid and coutaric (coumaric tartaric) acid are the most abundant hydroxycinnamates in grape juice prepared with minimal skin contact. ${ }^{45}$ In the intact berry, the hydroxycinnamates, predominately present in the vacuole, are not in contact with grape polyphenol oxidase (PPO), which is located in the cytoplasm, due to different cell membrane systems. ${ }^{42}$ However, when the berry is crushed in the presence of oxygen, the membrane systems are disrupted and enzymatic oxidation (catalyzed by PPO) converts these hydroxycinnamates to the corresponding reactive electrophilic $o$-quinones. ${ }^{46,47}$ The cresolase activity of grape polyphenol oxidase first converts coutaric acid to caftaric acid before being oxidized further to caftaric acid quinone. ${ }^{46} \mathrm{GSH}$, with its mercapto group serving as an electron-rich nucleophilic center, substitutes into the electrophilic ring of the caftaric acid quinone. The vicinal dihydroxy ring of the caffeic acid moiety is regenerated by means of proton transfer and the equivalent of an enol shift. ${ }^{46}$ The product, a thioether known as 2-Sglutathionyl caftaric acid or grape reaction product (GRP), is not a substrate for further oxidation by PPO despite its $o$ dihydroxyphenol structure. ${ }^{9,48}$ In this manner, GSH traps the $o$ quinones in a colorless form and the formation of brown polymers is limited. ${ }^{46}$ If GSH is depleted in the juice, the caftaric acid quinone, being an oxidant, can oxidize GRP and other flavanols to be reduced back to caftaric acid. Furthermore, the caftaric acid quinone may also polymerize with caftaric acid to form a reoxidizable phenol. ${ }^{10}$ These polymerization reactions with $o$-quinones lead to the browning of grape juice. ${ }^{48}$ The hydroxycinnamic acid to GSH ratio of a must should hence present a good indication of its oxidation susceptibility with higher ratios leading to darker musts. A ratio of 0.9-2.2 characterizes a lightly colored must. Medium and dark colored musts are characterized by hydroxycinnamic acid to GSH ratios of $1.1-3.6$ and $3.8-5.9$, respectively. ${ }^{10}$ Although resistant to PPO, GRP is, however, a substrate for laccase produced by the fungus Botrytis cinerea, and further oxidation with the substitution by GSH in position 5 leads to the formation of 2,5-di-S-glutathionylcaftaric acid (GRP2). It does not seem as if GRP2 can be further oxidized by laccase under winemaking conditions. ${ }^{49}$ The reaction is very sensitive to the presence of oxygen and sulfur dioxide $\left(\mathrm{SO}_{2}\right) \cdot \mathrm{SO}_{2}$ inhibits $\mathrm{PPO},{ }^{50}$ which consequently prevents the formation of GRP. In such a case, a high level of free hydroxycinnamates with high browning potential is retained in the must. ${ }^{43}$

GSH added at $10 \mathrm{mg} / \mathrm{L}$ to Sauvignon blanc wine at bottling significantly decreased the yellow tint of the wine during a three year aging period compared to the control wine. ${ }^{11}$ This raised interest in the ability of GSH to protect white wine color during bottle aging when nonenzymatic oxidation reactions prevail. Nonenzymatic oxidation arises from the oxidation of phenolic compounds and the subsequent polymerization of oxidized products. Polymerization reactions between phenols and other wine constituents, including acetaldehyde and glyoxylic acid may also give rise to browning pigments. The phenolic compounds most susceptible to chemical oxidation in wine include caffeic acid and its esters, catechin, epicatechin, and gallic acid. ${ }^{42}$ It has been demonstrated that sufficient amounts of GSH could inhibit oxidative coloration by delaying the formation of carboxymethine-bridged (+)-catechin dimers formed in the model wine system. ${ }^{51}$ Sonni et al. ${ }^{52}$ showed that this delay was due to the ability of GSH to form addition products with carbonyl compounds, such as glyoxylic acid. Furthermore, these authors proved that the inhibiting effect of GSH on glyoxylic acid-derived dimer formation was independent of temperature $\left(20\right.$ vs $\left.45^{\circ} \mathrm{C}\right)$ or the presence of copper and iron. In addition, the authors also reported the formation of another product in which GSH reacts with an intermediate 
compound in the production of the dimer, interrupting the polymerization reactions. This inhibition of carbonyl-derived polymerization reactions hinders the formation of unwanted pigments such as the yellow xanthylium cation, which may induce color changes that are negatively correlated with wine quality. It thus seems as if GSH could exert a protective effect on wine color during aging. However, these studies were conducted in model wine solutions under temperature and oxygen levels higher than normally present during wine aging. Further investigation under conditions more relevant to wine aging is thus needed to produce more conclusive results.

\section{IMPACT OF GLUTATHIONE ON AROMA COMPOUNDS IN MUST AND WINE}

Esters and Terpenes. Esters of higher alcohols and ethyl esters positively contribute to wine quality by imparting fruity aromas. ${ }^{53}$ Terpenes constitute an important aromatic group in several grape varieties and their corresponding wines such as the Muscat wines, Gewürztraminer, Weisser Riesling, and Bukettraube. Terpenes, such as linalool, $\alpha$-terpineol, nerol, geraniol, and hotrienol, impart floral, rose-like, perfumy, coriander, and campherous characters in wine. ${ }^{54}$ Papadopoulou and Roussis ${ }^{12}$ evaluated the effect of GSH and $N$-acetylcysteine on the decrease of volatile esters and terpenes in both Debina white wine and a model wine solution during aging. GSH inhibited the decline of several volatiles such as isoamyl acetate, ethyl hexanoate, ethyl octanoate, ethyl decanoate, and linalool in Debina wine during storage. ${ }^{12} \mathrm{GSH}$ added at $20 \mathrm{mg} / \mathrm{L}$ to dry Muscat wine inhibited the disappearance of linalool and $\alpha$ terpineol during storage of the wine. ${ }^{55}$ In the model wine solution, GSH inhibited the decrease of isoamyl acetate, ethyl hexanoate, and linalool in a dose-dependent manner. A low free sulfur dioxide wine $(35 \mathrm{mg} / \mathrm{L})$ supplemented with $20 \mathrm{mg} / \mathrm{L}$ GSH was more effective in protecting several esters and linalool compared to a wine with $50 \mathrm{mg} / \mathrm{L}$ free $\mathrm{SO}_{2}{ }^{56}$ The loss of volatile compounds may be ascribed to oxidation and other chemical reactions taking place. The ester concentration in wine may change due to esterification and hydrolysis reactions taking place. ${ }^{57}$ Furthermore, most terpene alcohols are replaced by terpene oxides, whereas linalool may convert to $\alpha$-terpineol, which has a much higher sensory threshold. ${ }^{58}$ The protective effect of GSH on some esters and terpenes during wine storage was ascribed to its free sulfhydryl ( $\mathrm{SH})$ moiety, ${ }^{59}$ which confers unique redox and nucleophilic properties. ${ }^{2}$ However, the exact mode by which GSH protects esters necessitates further research.

Volatile Thiols. Protection of Volatile Thiols. Varietal thiols such as 4-mercapto-4-methylpentan-2-one (4MMP), 3mercaptohexan-1-ol (3MH), and 3-mercaptohexylacetate (3MHA) have been identified as important contributors to the varietal aroma of Sauvignon blanc wine. ${ }^{60-63}$ These thiols have also been identified in wines from other cultivars such as Colombard, Riesling, Semillon, Merlot, Cabernet Sauvignon, and Grenache. ${ }^{64-66}$ Volatile thiols are particularly susceptible to oxidation during storage, ${ }^{67-69}$ and it has been proposed that GSH plays an important role in the protection of these compounds during bottle aging. ${ }^{11,70}$ The addition of $10 \mathrm{mg} / \mathrm{L}$ GSH to Sauvignon blanc wine prior to bottling resulted in significantly higher $3 \mathrm{MH}$ levels compared to the control after three years of bottle aging. ${ }^{11}$ This is in agreement with recent findings by Ugliano et al., ${ }^{13}$ who reported that the addition of $20 \mathrm{mg} / \mathrm{L} \mathrm{GSH}$ prior to bottling generally resulted in wines with higher $3 \mathrm{MH}$ levels after six months of bottle aging. As previously mentioned, hydroxycinnamic acids in the wine can be oxidized to $o$-quinones in the presence of oxygen. These $o$ quinones can easily react with thiols via a Michael addition reaction. ${ }^{71}$ Furthermore, $o$-quinones can also generate peroxides through a series of coupled reactions that are notorious for their oxidative properties against thiols. ${ }^{72}$ The mechanism by which GSH exerts a protective effect on varietal thiols is proposed to be competition based. ${ }^{34} \mathrm{GSH}$, also being a thiol, may possibly compete with the aromatic thiols to bind to the $o$ quinones and consequently limit the loss of varietal aroma. ${ }^{73}$

Glutathione as Volatile Thiol Precursor. The varietal volatile thiols $4 \mathrm{MMP}$ and $3 \mathrm{MH}$ are not present in the grapes as free thiols but are released during alcoholic fermentation from grape-derived, nonvolatile precursors. ${ }^{62,74}$ Both cysteinylated and glutathionalyted precursors have been identified. $^{75-77}$ S-3-(Hexan-l-ol)-L-cysteine (Cys-3MH) was first identified as the precursor of $3 \mathrm{MH}$ in Sauvignon blanc juice. $^{75}$ Peyrot des Gachons et al. $^{76}$ then identified S-3(hexan-1-ol)-glutathione (Glut-3MH) as a pro-precursor of Cys-3MH in Sauvignon blanc juice, which was later also confirmed by Thibon et al. $^{78}$ 4-(4-Methylpentan-2-one)-Lcysteine (Cys-4MMP) and 4-S-glutathionyl-4-methylpentan-2one (Glut-4MMP) have been identified as potential precursors of 4MMP in Sauvignon blanc juice. ${ }^{79,80}$ Glutathione $S$ conjugates are involved in detoxification systems of living organisms. The enzyme glutathione $S$-transferase catalyzes the conjugation of GSH with toxic compounds. ${ }^{81,82}$ Thereafter, $\gamma$ glutamyltranspeptidase and carboxypeptidase eliminate the glutamic acid and glycine moieties, respectively, to yield the cysteine $S$-conjugate. ${ }^{83,84}$ However, $\gamma$-glutamyltranspeptidase has never been identified in grapes. ${ }^{85}$ The detoxification pathways in plants are activated by various stresses including senescence as well as abiotic (oxidation, injury) and biotic factors (pathogens). ${ }^{78}$ Indeed, Kobayashi et al. ${ }^{86}$ reported that Glut-3MH synthesis and the subsequent metabolism to Cys$3 \mathrm{MH}$ are enhanced by various environmental stress conditions through the activation of glutathione $S$-transferases. Furthermore, Thibon et al. ${ }^{87}$ demonstrated that Sauvignon blanc and Semillon must had considerably higher volatile thiol precursor concentrations when the grapes were infected with the fungus $B$. cinerea. Recent work showed that $B$. cinerea secreted metabolites that stimulated the production of $\mathrm{Cys}-3 \mathrm{MH}^{78}$ The hypothesis states that these metabolites stimulate the formation of $(E)$-2-hexenal that is conjugated to GSH and then broken down to Cys-3MH.

Hydrogen Sulfide $\left(\mathrm{H}_{2} \mathrm{~S}\right) . \mathrm{H}_{2} \mathrm{~S}$ contributes to the "reductive" off-flavor in wines with an odor that is often described as "rotten egg" or putrefaction. Its detection threshold corresponds to $1.6 \mu \mathrm{g} / \mathrm{L}$ in white wine. ${ }^{88}$ Several factors influence the concentration of $\mathrm{H}_{2} \mathrm{~S}$ produced during alcoholic fermentation such as the presence of sulfur compounds, yeast strain, fermentation conditions, and the nutritional status of the grape juice. ${ }^{89,90}$ It is postulated that GSH may also be a potential source of $\mathrm{H}_{2} \mathrm{~S}$ because cysteine, a constituent amino acid, can be degraded by cysteine desulfhydrase to form $\mathrm{H}_{2} \mathrm{~S}$. ${ }^{91}$ Preliminary findings by Hallinan et al. ${ }^{92}$ suggest that GSH may contribute up to $40 \%$ of the $\mathrm{H}_{2} \mathrm{~S}$ liberated by nitrogen-starved yeast incubated in the presence of sulfate. When $S$. cerevisae cells were preincubated in a medium containing buthionine-( $S, R)$-sulfoximine (BSO), a specific inhibitor of GSH synthesis, $\mathrm{H}_{2} \mathrm{~S}$ liberation was suppressed by 75 and $45 \%$ during the first and second hours, respectively, after being transferred to a nitrogen-deficient medium. 
Recently, it has also been proven that Sauvignon blanc wines treated with GSH prior to bottling accumulated higher $\mathrm{H}_{2} \mathrm{~S}$ levels during bottle aging compared to untreated wines. This effect was amplified under low oxygen conditions and the presence of elevated copper(II) concentrations. The authors ascribed the higher $\mathrm{H}_{2} \mathrm{~S}$ accumulation to the antioxidant capacity of GSH causing reductive conditions, which promote $\mathrm{H}_{2} \mathrm{~S}$ production. ${ }^{13}$ Further research to elucidate the role of GSH in $\mathrm{H}_{2} \mathrm{~S}$ production is, however, much needed.

\section{REDUCTION OF ATYPICAL AGING CHARACTER}

Sotolon and 2-Aminoacetophenone. Sotolon (4,5dimethyl-3-hydroxy-2(5)H-furanone) is a volatile compound with an intense curry odor, and its perception threshold corresponds to $8 \mu \mathrm{g} / \mathrm{L}$ in wine. ${ }^{93}$ This furanone contributes to the aromas of "vins jaunes" (yellow wines) from the Jura and sherries. ${ }^{94,95}$ as well as dried fig and rancid nuances in French fortified wines and Port. ${ }^{96,97}$ The contribution of sotolon to the atypical aging character of dry white wines has been established. ${ }^{70,98,99}$ 2-Aminoacetophenone (2-AAP) is an atypical aging off-flavor in wine, which confers wet wool, fusel alcohol, naphthalene, and furniture polish aromas if present in concentrations that exceed its sensory threshold of $0.5-1.5 \mu \mathrm{g} / \mathrm{L}$ in wine. ${ }^{100,101}$ This compound has been detected in German white wines since the late 1980 s. ${ }^{101,102}$ GSH added at $10 \mathrm{mg} / \mathrm{L}$ to Sauvignon blanc wine at bottling has been shown to limit the formation of both these atypical aging off-odors during three years of storage. ${ }^{11}$ The sotolon concentration in the control wine exceeded its perception threshold of $8 \mu \mathrm{g} / \mathrm{L}$ in wine, whereas the addition of GSH inhibited its development to levels below its threshold. Although the levels of 2-aminoacetophenone were still lower than the perception threshold, it is evident that GSH suppressed the formation of this compound by almost half. No mechanism was proposed by the authors, and further research is required to elucidate the inhibitory effect GSH has on the development of atypical aging characters in wine.

Glutathione and Malolactic Fermentation (MLF). Reports on GSH in relation to MLF are scant. Only two studies have been done: one on the effect of GSH on MLF and one on the influence of MLF on GSH levels in wine. Rauhut et al. ${ }^{103}$ observed that the addition of GSH to low-pH wines promoted the growth of Oenococcus oeni and accelerated the speed of MLF. Marchand and de Revel ${ }^{104}$ evaluated the reduced, oxidized, and total glutathione content of five Merlot wines before and after MLF. Their results showed that no tendency could be deduced from the individual GSH or GSSG quantifications, although the reduced GSH content generally seemed to either stay constant or decrease during MLF. However, total GSH content decreased significantly during MLF (between 21 and 36\% for the five samples). Further investigation regarding the influence of GSH on MLF is, however, required.

Glutathione-Enriched Inactive Dry Yeast Preparations. The use of inactive dry yeast (IDY) preparations in winemaking is currently gaining interest due to its wide range of claimed applications. Commercial inactive yeast preparations are manufactured from thermal inactivation of the yeast $S$. cerevisiae grown in a highly concentrated sugar medium under aerobic conditions. ${ }^{105}$ In a recent review by Pozo-Bayón et al., ${ }^{105}$ IDY preparations were classified into four categories: inactive yeast (obtained by thermal inactivation prior to drying), yeast autolysates (intracellular content is partly degraded by an incubation step releasing vacuolar enzymes prior to thermal inactivation), yeast hulls or walls (the insoluble component of yeast walls excluding the cytoplasmic content), and yeast extracts (soluble extract after the total degradation of the cytoplasmic content). Studies to determine the natural thiol content in terms of GSH and free and protein cysteine in enological dry active yeasts have been done. ${ }^{73}$ GSH levels ranging from 39 to $0.92 \mathrm{mmol} / 100 \mathrm{~g}$ were reported. The thiol contents of different commercial samples of yeast mannoproteins, hulls, lysates, and extracts were also analyzed. Different from what was expected, the yeast extracts, being the soluble extract of the cytoplasmic content, and GSH, being a cytoplasmic component, did not contain GSH. Indeed, it was the lysate products that displayed the highest GSH content (up to $4.6 \mathrm{mmol} / 100 \mathrm{~g}){ }^{73}$ Traditionally, IDY preparations have been mainly used to improve alcoholic and malolactic fermentation, but their use to enhance the wine sensory characteristics has recently received much attention. ${ }^{105}$ Several commercial IDY products currently available on the market claim to preserve wine aroma, extend the shelf life of bottled wines, and delay the development of oxidized notes and the yellowing of white wine. The protective effect of these products is ascribed to the high GSH content with reductive properties. Glutathione-enriched inactive dry yeast preparations (GSHIDYs) all claim to boost wine GSH content either by the liberation of GSH into the wine or by allowing the yeast to assimilate GSH precursors during alcoholic fermentation for increased GSH production. However, the required optimum dose and the effects of other winemaking parameters such as temperature, $\mathrm{SO}_{2}$, and $\mathrm{pH}$ on its efficacy remain unknown.

Kritzinger et al. ${ }^{31}$ and Andújar-Ortiz et al. ${ }^{35}$ tested the amount of total and reduced GSH released into synthetic wines by commercial GSH-IDYs. When the preparations were added at the recommended dosage of $0.3 \mathrm{~g} / \mathrm{L}$, between 1 and $2 \mathrm{mg} / \mathrm{L}$ GSH was released into the synthetic wine, ${ }^{35}$ which corroborates data by Kritzinger et al., ${ }^{31}$ who reported five GSH-IDYs to release between 1.45 and $2.53 \mathrm{mg} / \mathrm{L}$ GSH into synthetic wine solutions $30 \mathrm{~min}$ after supplementation. The total GSH contents released ranged from 1.82 to $2.72 \mathrm{mg} / \mathrm{L},{ }^{35}$ which is also similar to results reporting total GSH levels in the range of $1.63-3.44 \mathrm{mg} / \mathrm{L}^{31}$ In addition, Kritzinger et al. ${ }^{31}$ analyzed the GSSG content of the GSH-IDYs, which revealed great variation among the different products. This illustrates the importance of differentiating between GSH and total GSH contents because it is the reduced form that is the active antioxidant in wine. However, further investigation to establish the effectiveness of the GSH released by these preparations in inhibiting wine oxidation is necessary. No literature could be found on the industrial preparation of GSH-IDYs, and it is not known whether exogenous GSH enrichment is allowed during the manufacturing process, although it has been previously proposed. $^{72}$

When the GSH-IDYs were implemented in winemaking trials, the difference in the total GSH content for the control wine and the GSH-IDY supplemented wine was higher than expected, taking into account the amount of GSH released by the specific GSH-IDY preparation, which was determined in the synthetic wine experiment. ${ }^{35}$ Analysis of the nitrogen composition of the wines revealed a much higher amino acid and peptide content for the GSH-IDY wine compared to the control. ${ }^{35}$ This led to the hypothesis that the higher nitrogen content in the GSH-IDY wine stimulated the production of GSH by $S$. cerevisiae during alcoholic fermentation. However, 
Table 1. Methods for the Analysis of GSH and/or GSSG in Grape Juice and Wine

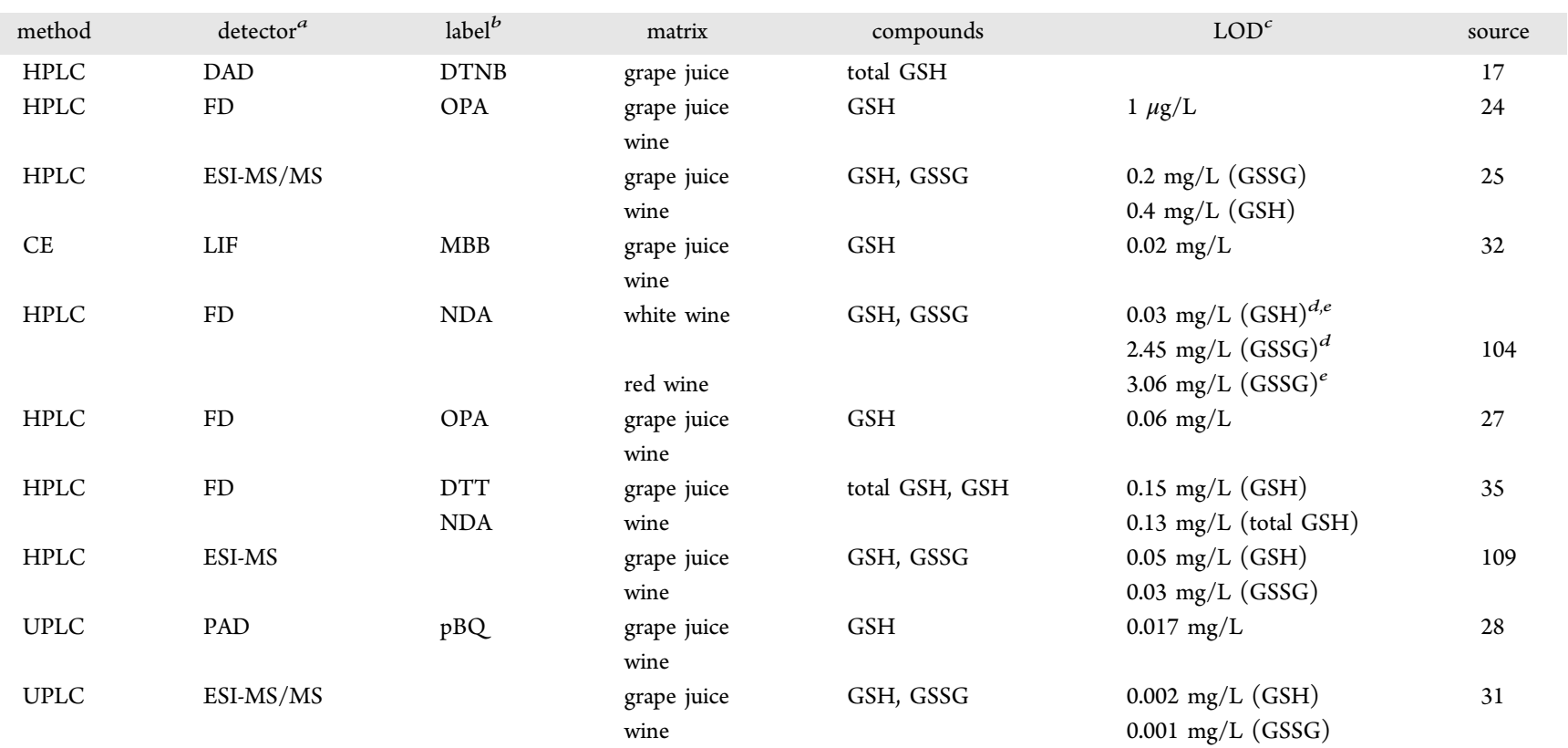

${ }^{a} \mathrm{DAD}$, diode array detector; FD, fluorescence director; ESI-MS/MS, electrospray ionization tandem mass spectrometry; PAD, photoarray detector. ${ }^{b}$ DTNB, 5,5-dithiobis(2-nitrobenzoic acid)/Ellman's reagent; OPA, o-phthaladehyde; MBB, monobromobimane; DTT, dithiothretiol; NDA, 2,3naphthalenedialdehyde; $\mathrm{pBQ}$ parabenzoquinone. ${ }^{c} \mathrm{LOD}$, limit of detection. ${ }^{d}$ White wine. ${ }^{e}$ Red wine.

no statistical differences in GSH content were observed between the control and the GSH-IDY-supplemented wine after alcoholic fermentation. The authors explained this phenomenon by a rapid oxidation of GSH released from the GSH-IDY during alcoholic fermentation. However, a drastic decrease in GSH concentration during alcoholic fermentation due to oxidation is probably unlikely, due to the reductive environment during this process. Indeed, Kritzinger et al. ${ }^{31}$ analyzed the GSSG levels for GSH-IDY-supplemented wine, and the levels remained very low $(<0.7 \mathrm{mg} / \mathrm{L})$ during alcoholic fermentation. In addition, Kritzinger et al. ${ }^{31}$ conducted a study to determine the optimal addition time of GSH-IDY during alcoholic fermentation that would result in the highest GSH levels post alcoholic fermentation. The difference between the GSH content of the control and treatments that were supplemented directly after yeast inoculation or a third into alcoholic fermentation was approximately $7-8 \mathrm{mg} / \mathrm{L}$. This was 4-5-fold higher than the amount of GSH released from the specific GSH-IDY into the model solution, which was approximately $1.6 \mathrm{mg} / \mathrm{L}$. This led to the hypothesis that the nutrients provided by the GSH-IDY preparation (free amino acids, peptides, etc.) supplemented directly after yeast inoculation or after a third of alcoholic fermentation had been completed led to increased GSH synthesis and subsequent release by the yeast compared to the control. The fact that the GSH content of the treatment that received a GSH-IDY supplementation two-thirds into alcoholic fermentation did not differ from the control may have been due to the fact that the supplementation was made too late during alcoholic fermentation for the yeast to benefit from the increased nutrients to synthesize and release GSH. Another explanation for the increased GSH levels observed for the treatments that were supplemented directly after yeast inoculation or a third into alcoholic fermentation is the preferential uptake of the nutrients provided by the GSH-IDY over GSH early during fermentation, which resulted in higher
GSH levels at the end of alcoholic fermentation. The lack of nutrient enrichment during the early stages of fermentation in the control and the treatment that received a GSH-IDY supplementation two-thirds into alcoholic fermentation may have caused the uptake of GSH by the yeast with the consequent decrease in GSH levels in the must and/or wine.

The proposed stimulating effect of amino acids on GSH synthesis by the yeast under winemaking conditions with the subsequent increase in wine GSH levels should be further examined. Although several authors have used amino acid addition strategies to enhance GSH production in S. cerevisiae, the GSH produced had always been in the intracellular form. ${ }^{105,106}$ Even though Gex1, a GSH/proton antiport transporting GSH to the extracellular medium, has recently been identified in $S$. cerevisiae, ${ }^{39}$ little or no information exists as to how and under which conditions GSH is secreted by yeast. The exact mechanism by which GSH-IDYs lead to increased GSH levels in wine thus needs to be elucidated.

\section{ANALYTICAL METHODS FOR GLUTATHIONE QUANTIFICATION}

As a result of the increasing interest in GSH, different analytical methods have been developed for the determination of reduced, oxidized, and total glutathione in grapes, must, wine, and inactive dry yeast preparations. Enzymatic methods based on the reaction of GSH with 5,5'-dithiobis(2-nitrobenzoic acid) (DTNB) to yield 2-nitro-5-thiobenzoic acid, which allows spectrophotometric absorption at $412 \mathrm{~nm}$, have been used for the determination of total GSH in berries, rachis, and grapevine leaves ${ }^{18}$ as well as white wine. ${ }^{107}$ Several liquid chromatography methods as well as a capillary electrophoresis method have been developed for the quantification of GSH and/or GSSG in grape juice and wine, which are summarized in Table 1. Many of these methods are time-consuming, requiring extensive sample preparation and derivatization. Moreover, the derivatization step could possibly contribute to variability and matrix 
effects. $^{109}$ The most recent published methods on GSH quantification in wine-related systems do not require derivatization; $^{31,108,109}$ instead, high dosages of sulfur dioxide and ascorbic acid are used to inhibit oxidation of GSH. With recent advances in analytical technologies, methods with short analysis times and excellent sensitivities have been developed, allowing the routine analysis of large numbers of samples, which could add significant value to GSH-related research in wine. However, standardized protocols for sample collection and pretreatment are required to minimize the margin of error in GSH quantification.

It is clear that GSH can play a central role in wine quality and longevity. However, as discussed in this review, many unknowns remain regarding the role of GSH in grapes and wine. Developments in analytical chemistry should assist in the further elucidation of its role in the chemical and sensory composition of grapes and wines.

\section{AUTHOR INFORMATION}

\section{Corresponding Author}

*Phone: +27 21808 2022. Fax: +27 21808 3771. E-mail: wdutoit@sun.ac.za.

\section{Notes}

The authors declare no competing financial interest.

\section{REFERENCES}

(1) Anderson, M. E. Glutathione: an overview of biosynthesis and modulation. Chem.-Biol. Interact. 1998, 112, 1-14.

(2) Penninckx, M. J. A short review on the role of glutathione in the response of yeasts to nutritional, environmental, and oxidative stresses. Enzyme Microb. Technol. 2000, 26, 737-742.

(3) Fahey, R. C. Novel thiols of prokaryotes. Annu. Rev. Microbiol. 2001, 55, 533-556.

(4) Li, Y.; Wei, G.; Chen, J. Glutathione: a review on biotechnological production. Appl. Microbiol. Biotechnol. 2004, 66, 233-242.

(5) Carmel-Harel, O.; Storz, G. Roles of the glutathione- and thioredoxin-dependent reduction systems in the Escherichia coli and Saccharomyces cerevisiae responses to oxidative stress. Annu. Rev. Microbiol. 2000, 54, 439-461.

(6) Pastore, A.; Federici, G.; Bertini, E.; Piemonte, F. Analysis of glutathione: implication in redox and detoxification. Clin. Chim. Acta 2003, 333, 19-39.

(7) Penninckx, M. J. An overview on glutathione in Saccharomyces versus non-conventional yeasts. FEMS Yeast Res. 2002, 295-305.

(8) Singleton, V. L.; Salgues, J.; Zaya, J.; Trousdale, E. Caftaric acid disappearance and conversion to products of enzymatic oxidation in grape must and wine. Am. J. Enol. Vitic. 1985, 36, 50-56.

(9) Singleton, V. L.; Cilliers, J. J. L. Phenolic browning: a perspective from grape and wine. Research Enzymatic Browning and Its Prevention. ACS Symp. Ser. 1995, No. 600, 23-48.

(10) Du Toit, W. J.; Marais, J.; Pretorius, I. S.; Du Toit, M. Oxygen in wine: a review. S. Afr. J. Enol. Vitic. 2006, 27, 76-94.

(11) Dubourdieu, D.; Lavigne-Cruège, V. The role of glutathione on the aromatic evolution of dry white wine. Wine Internet Technical Journal, 02, 2; http://infowine.com.

(12) Papadopoulou, D.; Roussis, I. G. Inhibition of the decrease of volatile esters and terpenes during storage of a white wine and a model wine medium by glutathione and $\mathrm{N}$-acetyl-cysteine. Int. J. Food Sci. Technol. 2008, 43, 1053-1057.

(13) Ugliano, M.; Kwiatkowski, M. J.; Vidal, S.; Capone, D.; Siebert, T.; Dieval, J. B.; Aagaard, O.; Waters, E. J. Evolution of 3mercatohexanol, hydrogen sulfide, and methyl mercaptan during bottle storage of Sauvignon blanc wines. Effect of glutathione, copper, oxygen exposure, and closure-derived oxygen. J. Agric. Food Chem. 2011, 59, 2564-2572.
(14) Leustek, T.; Martin, M.; Bick, J.; Davies, J. Pathways and regulation of sulfur metabolism revealed through molecular and genetic studies. Annu. Rev. Plant Physiol. Plant Mol. Biol. 2000, 51, $141-165$.

(15) Meister, A. Glutathione metabolism and its selective modification. J. Biol. Chem. 1988, 263, 17205-17208.

(16) Noctor, G.; Foyer, C. Ascorbate and glutathione: keeping active oxygen under control. Annu. Rev. Plant Physiol. Plant Mol. Biol. 1998, 49, 249-279.

(17) Cheynier, V.; Souquet, J. M.; Moutounet, M. Glutathione content and glutathione to hydroxycinnamic acid ratio in Vitis vinifera grapes and musts. Am. J. Enol. Vitic. 1989, 40, 320-324.

(18) Adams, D. O.; Liyanage, C. Glutathione increases in grape berries at the onset of ripening. Am. J. Enol. Vitic. 1993, 44, 333-338.

(19) Okuda, T.; Yokotsuka, K. Levels of glutathione and activities of related enzymes during ripening of Koshu and Cabernet Sauvignon grapes and during winemaking. Am. J. Enol. Vitic. 1999, 50, 264-270.

(20) Šuklje, K.; Lisjak, K.; Baša Česnik, H.; Janeš, L.; Vanzo, A.; du Toit, W.; Coetzee, Z.; Deloire, A. Classification of grape berries according to diameter and total soluble solids to study the effect of light and temperature on methoxypyrazines, glutathione and hydroxycinnamates evolution during ripening of Sauvignon blanc. J. Agric. Food Chem. 2012, 60, 9454-9461.

(21) Liyanage, C.; Adams, D. O. Glutathione content of grape leaves and berries at the onset of ripening (abstract). Am. J. Enol. Vitic. 1992, 43, 304.

(22) Choné, X.; Lavigne-Cruège, V.; Tominaga, T.; Van Leeuwen, C.; Castagnede, C.; Saucier, C.; Dubourdieu, D. Effect of vine nitrogen status on grape aromatic potential: flavor precursors ( $S$-cysteine conjugates), glutathione and phenolic content in Vitis vinifera L. cv. Sauvignon blanc grape juice. J. Int. Sci. Vigne Vin 2006, 40, 1-6.

(23) Lacroux, F.; Tregoat, O.; Van Leeuwen, C.; Pons, A.; Tominaga, T.; Lavigne-Cruège, V.; Dubourdieu, D. Effect of foliar nitrogen and sulphur application on aromatic expression of Vitis vinifera L. cv. Sauvignon blanc. J. Int. Sci. Vigne Vin 2008, 42, 125-132.

(24) Park, S. K.; Boulton, R. B.; Noble, A. C. Formation of hydrogen sulfide and glutathione during fermentation of white grape musts. Am. J. Enol. Vitic. 2000, 51, 91-97.

(25) Du Toit, W. J.; Lisjak, K.; Stander, M.; Prevoo, D. Using LCMSMS to assess glutathione levels in South African white grape juices and wines made with different levels of oxygen. J. Agric. Food Chem. 2007, 55, 2765-2769.

(26) Maggu, M.; Winz, R.; Kilmartin, P. A.; Trought, M. C. T.; Nicolau, L. Effect of skin contact and pressure on the composition of Sauvignon blanc must. J. Agric. Food Chem. 2007, 55, 10281-10288.

(27) Janes, L.; Lisjak, K.; Vanzo, A. Determination of glutathione content in grape juice and wine by high-performance liquid chromatography with fluorescence detection. Anal. Chim. Acta 2010, 674, 239-242.

(28) Fracassetti, D.; Lawrence, N.; Tredoux, A. G. J.; Tirelli, A.; Nieuwoudt, H. H.; du Toit, W. J. Quantification of glutathione, catechin and caffeic acid in grape juice and wine by a novel ultraperformance liquid chromatography method. Food Chem. 2011, 128, $1136-1142$.

(29) Kritzinger, E. C. Winemaking practices affecting glutathione concentrations in white wine. M.Sc. Agric. Thesis, Stellenbosch University, Matieland, South Africa, 2012.

(30) Patel, P.; Herbst-Johnstone, M.; Lee, S. A.; Gardner, R. C.; Weaver, R.; Nicolau, L.; Kilmartin, P. A. Influence of juice pressing conditions on polyphenols, antioxidants and varietal aroma of Sauvignon blanc microferments. J. Agric. Food Chem. 2010, 58, $7280-7288$

(31) Kritzinger, E. C.; du Toit, W. J.; Stander, M. A. Assessment of glutathione levels in model solution and grape ferments supplemented with glutathione-enriched inactive dry yeast preparations using a novel UPLC-MS/MS method. Food. Addit. Contam. Part A 2012, DOI: $10.1080 / 19440049.2012 .728723$.

(32) Lavigne, V.; Pons, A.; Dubourdieu, D. Assay of glutathione in must and wines using capillary electrophoresis and laser-induced 
fluorescence detection - changes in concentration in dry white wines during alcoholic fermentation and aging. J. Chromatogr., A 2007, 1139, 130-135.

(33) Park, S. K.; Boulton, R. B.; Noble, A. C. Automated HPLC analysis of glutathione and thiol-containing compounds in grape juice and wine using pre-column derivatization with fluorescence detection. Food Chem. 2000, 68, 475-480.

(34) Fracassetti, D. Investigation on cysteinyl thiol compounds from yeast affecting wine properties. Ph.D. Thesis, Technology and Biotechnology, University of Milan, Italy, 2010.

(35) Andújar-Ortiz, I.; Pozo-Bayón, M. A.; Moreno-Arribas, M. V.; Martín-Álvarez, P. J.; Rodríguez-Bencomo, J. J. Reversed-phase highperformance liquid chromatography-fluorescence detection for the analysis of glutathione and its precursor $\gamma$-glutamyl cysteine in wines and model wines supplemented with oenological inactive dry yeast preparations. Food Anal. Methods 2012, 5, 154-161.

(36) Coetzee, C. Oxygen and sulphur dioxide additions to Sauvignon blanc: effect on must and wine composition. M.Sc. Agric. Thesis, Stellenbosch University, Matieland, South Africa, 2011.

(37) Miyake, T.; Hazu, T.; Yoshida, S.; Kanayama, M.; Tomochika, K.; Shinoda, S.; Ono, B. Glutathione transport systems of the budding yeast Saccharomyces cerevisiae. Biosci., Biotechnol., Biochem. 1998, 62, $1858-1864$

(38) Bourbouloux, A.; Shahi, P.; Chakladar, A.; Delrot, S.; Bachhawat, A. K. Hgtlp, a high affinity glutathione transporter from the yeast Saccharomyces cerevisiae. J. Biol. Chem. 2000, 275, 1325913265 .

(39) Dhaoui, M.; Auchère, F.; Blaiseau, P. L.; Lesuisse, E.; Landoulsi, A.; Camadro, J. M.; Haguenauer-Tsapis, R.; Belgareh-Touzé, N. Gex1 is a yeast glutathione exchanger that interferes with $\mathrm{pH}$ and redox homeostasis. Mol. Biol. Cell 2011, 22, 2054-2067.

(40) Lisjak, $\mathrm{K}$. The role of oxygen in new vinification technologies of white and red wines. Ph.D. Thesis (Food Science and Technology), Biotechnical Faculty, University of Ljubljana, Slovenia, 2007.

(41) Penna, N. C.; Daudt, C. E.; Brendel, M.; Henriques, J. A. P. Evolución de los niveles de glutathiona y ésteres hidroxicinámicos durante la vinificación de Sauvignon blanc, Chenin blanc, Niágara y Tannat. Alimentaria 2001, 326, 147-151.

(42) Li, H.; Guo, A.; Wang, H. Mechanisms of oxidative browning of wine. Food Chem. 2008, 108, 1-13.

(43) Oliveira, C. M.; Ferreira, A. C. S.; De Freitas, V.; Silva, A. M. S. Oxidation mechanisms occurring in wines. Food Res. Int. 2011, 44, $1115-1126$.

(44) Betes-Saura, C.; Andres-Lacueva, C.; Lamuela-Raventos, R. M. Phenolics in white free run juices and wines from Penedès by highperformance liquid chromatography: Changes during vinification. $J$. Agric. Food Chem. 1996, 44, 3040-3046.

(45) Cheynier, V. F.; van Hulst, M. W. J. Oxidation of trans-caftaric acid and 2-S-glutathionylcaftaric acid in model solutions. J. Agric. Food Chem. 1988, 36, 10-15.

(46) Singleton, V. L.; Salgues, M.; Zaya, J.; Trousdale, E. Caftaric acid disappearance and conversion to products of enzymatic oxidation in grape must and wine. Am. J. Enol. Vitic. 1985, 36, 50-56.

(47) Cilliers, J. J. L.; Singleton, V. L. Caffeic acid autoxidation and the effects of thiols. J. Agric. Food Chem. 1990, 38, 1789-1796.

(48) Salgues, M.; Cheynier, V.; Gunata, Z.; Wylde, R. Oxidation of grape juice 2-S glutathionyl caffeoyl tartaric acid by Botrytis cinerea laccase and characterization of a new substance. 2,5-Di-S-glutathionyl caffeoyl tartaric acid. J. Food Sci. 1986, 51, 1191-1194.

(49) Boulton, R. B.; Singleton, V. L.; Bisson, L. F.; Kunkee, R. E. Principles and Practices of Winemaking; Boulton, R. B., Ed.; Chapman and Hall: New York, 1996.

(50) Dubernet, M.; Ribereau-Gayon, P. Presence et significance dans les moutes et les vins de la tyrosine du raisin. Connaiss. Vigne Vin 1973, 7, 283-302.

(51) Sonni, F.; Clark, A. C.; Prenzler, P. D.; Riponi, C.; Scollary, G. R. Antioxidant action of glutathione and the ascorbic acid/glutathione pair in a model white wine. J. Agric. Food Chem. 2011, 59, 3940-3949.
(52) Sonni, F.; Moore, E. G.; Clark, A. C.; Chinnici, F.; Riponi, C.; Scollary, G. R. Impact of glutathione on the formation of methylmethine- and carboxymethine-bridged $(+)$-catechin dimers in a model wine system. J. Agric. Food Chem. 2011, 59, 7410-7418.

(53) Etievant, P. X. Wine. In Volatile Compounds in Foods and Beverages, 1st ed.; Maarse, H., Ed.; Dekker: New York, 1991; pp 483546.

(54) Marais, J. Terpenes in the aroma of grapes and wines: a review. S. Afr. J. Enol. Vitic. 1983, 4, 49-60.

(55) Papadopoulou, D.; Roussis, I. G. Inhibition of the decline of linalool and $\alpha$-terpineol in muscat wines by glutathione and $\mathrm{N}$-acetylcysteine. Int. J. Food Sci. 2001, 13, 413-419.

(56) Roussis, I. G.; Lambropoulos, I.; Tzimas, P. Protection of volatiles in a wine with low sulfur dioxide by caffeic acid or glutathione. Am. J. Enol. Vitic. 2007, 58, 274-278.

(57) Ramey, D. D.; Ough, C. S. Volatile ester hydrolysis or formation during storage of model solutions and wines. J. Agric. Food Chem. 1980, 28, 928-934.

(58) Jackson, R. S. Postfermentation treatments and related topics. In Wine Science. Principles and Applications, 3rd ed.; Jackson, R. S., Ed.; Academic Press: San Diego, CA, 2008; pp 445-447.

(59) Roussis, I. G.; Papadopoulou, D.; Sakarellos-Daitsiotis, M. Protective effect of thiols on wine aroma volatiles. Open Food Sci. J. 2009, 3, 98-102.

(60) Darriet, P.; Tominaga, T.; Lavigne, V.; Boidron, J.; Dubourdieu, D. Identification of a powerful aromatic compound of Vitis vinifera $\mathrm{L}$. var. Sauvignon wines: 4-mercapto-4-methylpentan-2-one. Flavour Fragrance J. 1995, 10, 385-392.

(61) Tominaga, T.; Darriet, P.; Dubourdieu, D. Identification of 3mercaptohexyl acetate in Sauvignon wine, a powerful aromatic compound exhibiting box-tree odor. Vitis 1996, 35, 207-210.

(62) Tominaga, T.; Furrer, A.; Henry, R.; Dubourdieu, D. Identification of new volatile thiols in the aroma of Vitis vinifera $\mathrm{L}$. var. Sauvignon blanc wines. Flavour Fragrance J. 1998, 13, 159-162.

(63) Coetzee, C.; du Toit, W. J. A comprehensive review on Sauvignon blanc aroma with a focus on certain positive volatile thiols. Food Res. Int. 2012, 45, 287-298.

(64) Tominaga, T.; Baltenweck-Guyot, R.; Des Gachons, C. P.; Dubourdieu, D. Contribution of volatile thiols to the aromas of white wines made from several Vitis vinifera grape varieties. Am. J. Enol. Vitic. 2000, 51, 178-181.

(65) Murat, M. L.; Tominaga, T.; Dubourdieu, D. Assessing the aromatic potential of Cabernet Sauvignon and Merlot musts used to produce rosé wine by assaying the cysteinylated precursor of 3mercaptohexan-1-ol. J. Agric. Food Chem. 2001, 49, 5412-5417.

(66) Ferreira, V.; Ortin, N.; Escudero, A.; Lopez, R.; Cacho, J. Chemical characterization of the aroma of Grenache rose wines: aroma extract dilution analysis, quantitative determination, and sensory reconstitution studies. J. Agric. Food Chem. 2002, 50, 4048-4054.

(67) Darriet, P. Caractérisation des composés volatils associés a la vigne et au vin: Applications technologiques. Ph.D. Thesis, Université Victor Segalen, Bordeaux, France, 2002.

(68) Blanchard, L.; Darriet, P.; Dubourdieu, D. Reactivity of 3mercaptphexanol in red wine: impact of oxygen, phenolic fractions, and sulfur dioxide. Am. J. Enol. Vitic. 2004, 55, 115-120.

(69) Makhotkina, O.; Pineau, B.; Kilmartin, P. A. Effect of storage temperature on the chemical composition and sensory profile of Sauvignon blanc wines. Austr. J. Grape Wine Res. 2012, 18, 91-99.

(70) Lavigne-Cruège, V.; Dubourdieu, D. Role of glutathione on development of aroma defects in dry white wines. In 13th International Enology Symposium; Trogus, H., Gafner, J., Sutterlin, A., Eds.; International Association of Enology: Montpellier, France, 2002; pp 331-347.

(71) Cheynier, V. F.; Trousdale, E. K.; Singleton, V. L.; Salgues, M. J.; Wylde, R. Characterization of 2-S-glutathioylcaftaric acid and its hydrolysis in relation to grape wines. J. Agric. Food Chem. 1986, 34, 217-221. 
(72) Wilderandt, H. L.; Singleton, V. L. The production of aldehydes as a result of oxidation of polyphenolic compounds and its relation to wine aging. Am. J. Enol. Vitic. 1974, 25, 119-126.

(73) Tirelli, A.; Fracassetti, D.; De Noni, I. Determination of reduced cysteine in oenological cell wall fractions of Saccharomyces cerevisiae. J. Agric. Food Chem. 2010, 58, 4565-4570.

(74) Swiegers, J. H.; Capone, D. L.; Pardon, K. H.; Elsey, G. M.; Sefton, M. A.; Francis, I. L.; Pretorius, I. S. Engineering volatile thiol release in Saccharomyces cerevisiae for improved wine aroma. Yeast 2007, 24, 561-574.

(75) Tominaga, T.; Peyrot Des Gachons, C.; Dubourdieu, D. A new type of flavour precursors in Vitis vinifera L. cv. Sauvignon blanc: $S$ cysteine conjugates. J. Agric. Food Chem. 1998, 46, 5215-5219.

(76) Peyrot des Gachons, C.; Tominaga, T.; Dubourdieu, D. Sulfur aroma precursor present in $S$-glutathione conjugate form: identification of S-3-(hexan-1-ol)-glutathione in must from Vitis vinifera $\mathrm{L}$. cv. Sauvignon blanc. J. Agric. Food Chem. 2002, 50, 4076-4079.

(77) Subileau, M.; Schneider, R.; Salmon, J. M.; Degryse, E. New insights on 3-mercaptohexanol (3MH) biogenesis in Sauvignon blanc wines: Cys-3MH and (E)-hexen-2-al are not the major precursor. $J$. Agric. Food Chem. 2008, 56, 9230-9235.

(78) Thibon, C.; Cluzet, S.; Merillon, J. M.; Darriet, P.; Dubourdieu, D. 3-Sulfanylhexanol precursor biogenesis in grapevine cells: the stimulating effect of Botrytis cinerea. J. Agric. Food Chem. 2011, 59, 1344-1351.

(79) Tominaga, T.; Masneuf, I.; Dubourdieu, D. A S-cysteine conjugate, precursor of aroma of white Sauvignon. J. Int. Sci. Vigne Vin 1995, 29, 227-232.

(80) Fedrizzi, B.; Pardon, K. H.; Sefton, M. A.; Elsey, G. M.; Jeffery, D. W. First identification of 4-S-glutathionyl-4-methylpentan-2-one, a potential precursor of 4-mercapto-4-methylpentan-2-one, in Sauvignon blanc juice. J. Agric. Food Chem. 2009, 57, 991-995.

(81) Habig, W. H.; Pabst, M. J.; Jakoby, W. B. Glutathione-Stransferases. The first enzymatic step in mercapturic acid formation. J. Biol. Chem. 1974, 249, 7130-7139.

(82) Vuilleumier, S. Bacterial glutathione S-transferases: what are they good for? J. Bacteriol. 1997, 179, 1431-1441.

(83) Jakoby, W. B.; Stevens, J.; Duffel, M. W.; Weisiger, R. A. The terminal enzymes of mercapturate formation and the thiomethyl shunt. Rev. Biochem. Toxicol. 1984, 6, 97-115.

(84) Wolf, A. E.; Dietz, K. J.; Schroder, P. Degradation of glutathione $S$-conjugates by a carboxypeptidase in the plant vacuole. FEBS Lett. 1996, 384, 31-34.

(85) Roland, A.; Schneider, R.; Guernevé, C. L.; Razungles, A.; Cavelier, F. Identification and quantification by LC-MS/MS of a new precursor of 3-mercaptohexan-1-ol $(3 \mathrm{MH})$ using stable isotope dilution assay: elements for understanding the $3 \mathrm{MH}$ production in wine. Food Chem. 2010, 121, 847-855.

(86) Kobayashi, H.; Takase, H.; Kaneko, K.; Tanzawa, F.; Takata, R.; Suzuki, S. Analysis of S-3-(hexan-1-ol)-glutathione and S-3-(hexan-1ol)-L-cysteine in Vitis vinifera L. cv. Koshu for aromatic wines. Am. J. Enol. Vitic. 2010, 61, 176-185.

(87) Thibon, C.; Dubourdieu, D.; Darriet, P.; Tominaga, T. Impact of noble rot on the aroma precursor of 3-sulfanylhexanol content in Vitis vinifera L. cv Sauvignon blanc and Semillon grape juice. Food Chem. 2009, 114, 1359-1364.

(88) Siebert, T.; Bramley, B.; Solomon, M. Hydrogen sulfide: aroma detection threshold study in white and red wines. Technol. Rev. 2009, $183,14-16$.

(89) Rauhut, D. Yeasts - production of sulphur compounds. In Wine Microbiology and Biochemistry; Fleet, G. H., Ed.; Harwood Academic Publishers: Chur, Switzerland, 1993; pp 183-223.

(90) Spiropoulos, A.; Tanaka, J.; Flerianos, I.; Bisson, L. F. Characterization of hydrogen sulphide formation in commercial and natural wine isolates of Saccharomyces. Am. J. Enol. Vitic. 2000, 51, 233-248.

(91) Tokuyama, T.; Kuraishi, H.; Aida, K.; Uemura, T. Hydrogen sulfide evolution due to a pantothenic acid deficiency in the yeast requiring this vitamin, with special reference to the effect of adenosine triphosphate on yeast cysteine desulfhydrase. J. Gen. Appl. Microbiol. 1973, 19, 439-466.

(92) Hallinan, C. P.; Saul, D. J.; Jiranek, V. Differential utilisation of sulfur compounds for $\mathrm{H}_{2} \mathrm{~S}$ liberation by nitrogen starved yeasts. Aust. J. Grape Wine Res. 1999, 5, 82-90.

(93) Lavigne, V.; Pons, A.; Darriet, P.; Dubourdieu, D. Changes in the sotolon content of dry white wines during barrel and bottle aging. J. Agric. Food Chem. 2008, 56, 2688-2693.

(94) Dubois, P.; Rigaud, J.; Dekimpe, J. Identification de la diméthyl4,5 tertrahydrofuranedione-2,3 dans le Vin Jaune du Jura. Lebensm. Wiss. Technol. 1976, 9, 366-368.

(95) Guichard, E.; Pham, T. T.; Etievant, P. Quantitative determination of sotolon in wines by high-performance liquid chromatography. Chromatographia 1993, 37, 539-541.

(96) Cutzach, I.; Chatonnet, P.; Dubourdieu, D. Rôle du sotolon dans l'arôme des vins doux naturels, influence des conditions d'élevage et de vieillissement. J. Int. Sci. Vigne Vin 1998, 32, 223-233.

(97) Silva Ferreira, A. C.; Barbe, J. C.; Bertrand, A. 3-Hydroxy-4,5dimethyl-2(5H)-furanone: a key odorant of the typical aroma of oxidative aged port wine. J. Agric. Food Chem. 2003, 51, 4356-4363.

(98) Escudero, A.; Cacho, J.; Ferreira, V. Isolation and identification of odorants generated in wine during its isolation: a gas chromatography-olfactometric study. Eur. Food Res. Technol. 2000, $211,105-110$.

(99) Ferreira, A. C. S.; Hogg, T.; Guedes de Pinho, P. Identification of key odorants related to the typical aroma of oxidation-spoiled white wines. J. Agric. Food Chem. 2003, 51, 1377-1381.

(100) Fan, W.; Tsai, I. M.; Qian, M. C. Analysis of 2-aminoacetophenone by direct-immersion solid-phase microextraction and gas chromatography-mass spectrometry and its sensory impact in Chardonnay and Pinot gris wines. Food Chem. 2007, 105, 1144-1150.

(101) Schmarr, H.; Ganß, S.; Sang, W.; Potouridis, T. Analysis of 2 aminoacetophenone in wine using a stable isotope dilution assay and multidimensional gas chromatography-mass spectrometry. J. Chromatogr., A 2007, 1150, 78-84.

(102) Rapp, A.; Versini, G.; Ullemeyer, H. 2-Aminoacetophenone: the causal agent of the untypical aging flavor (naphthalene note or hybrid note) of wine. Vitis 1993, 32, 61-62.

(103) Rauhut, D.; Gawron-Scibek, M.; Beisert, B.; Kondizior, M.; Schwarz, R.; Kürbel, H.; Großmann, M.; Krieger, S. Der Einfluss von $S$-haltigen Aminosäuren und Glutathion auf das Wachstum von Oenococcus oeni und die malolaktische Gärung. Weinqualität und biologischer Säureabbau: Zusammenfassung der Berichte des XVIes Entretiens Scientifiques Lallemand; Lallemand: Porto, Portugal, 2004; pp 2123.

(104) Marchand, S.; de Revel, G. A HPLC fluorescence-based method for glutathione derivatives quantification in must and wine. Anal. Chim. Acta 2010, 660, 158-163.

(105) Pozo-Bayón, M. A.; Andújar-Ortiz, I.; Moreno-Arribas, M. V. Scientific evidences beyond the application of inactive dry yeast preparations in winemaking. Food Res. Int. 2009, 42, 754-761.

(106) Wen, S.; Zhang, T.; Tan, T. Utilization of amino acids to enhance glutathione production in Saccharomyces cerevisiae. Enzyme Microb. Technol. 2004, 35, 501-507.

(107) Wang, Z.; Tan, S.; Song, J. Effect of amino acids addition and feedback control strategies on the high-cell-density cultivation of Saccharomyces cerevisiae for glutathione production. Process Biochem. 2007, 42, 108-111.

(108) Cassol, T.; Adams, D. O. Detection of glutathione in white wines using an enzymatic analytical method. Am. J. Enol. Vitic. 1995, 46, 410 .

(109) Mattivi, F.; Fedrizzi, B.; Zenato, A.; Tiefenthaler, P.; Tempesta, $S$. Development of reliable analytical tools for evaluating the influence of reductive winemaking on the quality of Lugana wines. Anal. Chim. Acta 2012, 732, 194-202. 